\title{
A mother's viewpoint
}

\section{Mrs. Helen Kushnick*}

On Oct 13, 1983, my 3-year-old son, Samuel Jared Kushnick, died as a result of Acquired Immune Deficiency Syndrome (AIDS). After birth, he received 20 blood transfusions from 13 separate donors in the neonatal unit of a hospital in Los Angeles, California.

Sam's death devastated our family, including his twin sister, Sara. Sam was not the first, but the fourth, premature male to die in Los Angeles during a six-month period, as a result of blood-transfusion-related AIDS. The first was in February 1983, the second in April, the third in June.

When my son died, pediatric AIDS was not considered a disease. I was told that our son's death would not be counted as an AIDS fatality because he hadn't reached the age of 5. My husband fought with the hospital administrators, including the head of the blood bank, for 45 minutes after Sam died to have AIDS listed on his death certificate as the cause of his death. What we didn't know was that once the mortuary saw AIDS as the cause of death, they refused to dress his body for burial. The insurance company that provided our medical coverage tried to claim a "pre-existing" condition so that they wouldn't have to pay the $\$ 94,000$ in medical costs for Sam's 19-day final hospital stay. For six months after he died, I received bills addressed to him on an almost daily basis. They lost. They paid. Then they cancelled our policy.

The first official statistics out of the Centers for Disease Control (CDC) were published in November 1984. Seventy-two pediatric cases had been recorded. There are now 456 recorded cases of pediatric $A I D S$, and the pediatric AIDS-related complex $(A R C)$ cases are not counted in these statistics.

During Sam's illness, our daughter was ostracized and rejected by a segment of our well-educated, affluent Beverly Hills community. Lack of public awareness of the correct facts concerning the transmission of AIDS caused these people to panic and to force nursery school administrators to expel Sara for fear she could contaminate the other children.

Even after the school and parents had been assured by leading pediatric immunologists and the Los Angeles County Health Department that Sara was perfectly healthy and that ADS was not communicable by casual contact, the public hysteria persisted, and we were forced to place Sara in another school.
Sara then started kindergarten in a public school. Our applications for private schools had been rejected. Although she had had the required medical examination and inoculations prior to her admission, I was called by the principal and asked for an additional letter from her doctor stating she was healthy. The school had received a number of calls from concerned parents, even though my daughter was exceptionally healthy and more than two years had passed since her brother's death.

In 1983, my family's decision to go public with our story seemed courageous. To us, it was simply a question of not having a choice. It was clear to us then that AIDS was not a homosexual disease, but a virus.

In my conversations with officials at the $C D C$ in 1984, it was obvious that the number of young victims of AIDS would be growing each year. Yet the cities have not come very far in the care and education of these children.

Let me tell you about my friend whom I'm going to Call "Mrs. Smith." She is black and a single parent. Her 3-year-old son also contracted AIDS through a blood transfusion. She has a daughter 6 years of age. She works as a teacher's aide. She tells no one that her son has AIDS because she doesn't feel she could fight the discrimination and isolation of herself and her daughter were the facts known.

The most horrendous part of this disease is fear and rejection. It is hard enough for an adult to cope with and impossible to explain to a child. This is the end result of our lack of education through proper channels. Until we find a vaccine or cure, the only way to stop the spread of AIDS is through education. We need effective educational programs, designed under the auspices of the Surgeon General, in every city and state in this nation-regardless of how few AIDS cases are statistically counted. As we know, the statistic have been wrong, and $A R C$ cases aren't even being counted. The public must become comfortable with the knowledge that quarantine is not the answer to preventing the spread of AIDS. Education is. And not after a child with $A I D S$ is admitted to school but before.

The citizen and physicians, practicing and academic, are still being correctly informed about $A I D S$. It is not appropriate that both the public and physicians receive most of their medical informa- 
tion through the news media, which has been the case with the AIDS crisis. The majority of the general public does not understand the difference between a specific test for a virus and an antibody test.

While there are now only a handful of postMarch, 1985, blood-tranfusion AIDS cases, these will surely grow. The same system existing when my son was infected is still in place. (Editor's note. It should be noted that federal law now requires HIV screening of blood for all transfusions in the United States.) Any physician will tell you that blood is a dangerous drug and there is still no standard of care across this nation for blood-tranfusion procedures in neonatal units. Yet the population at greatest risk for blood-transfusion AIDS continues to be the children, as the increased cases are showing us.

Most of the local school boards haven't even addressed the issue yet. They wait for crisis situations and then throw the child out of school while they figure out what to do. Shouldn't our citizens be able to go to their government for facts? Aren't the parents of school-aged children entitled to receive their facts from the board of education?

Government agencies have not effectively utilized educational media, such as television and radio. As a result, the news media has reported it's own version of events, which in some instances has been sensational, inaccurate, and has provided little public health information.

And what of the mothers like "Mrs. Smith"? Isn't she entitled to an effective support group? Having a critically ill child is a nightmare, one I hope none of you will ever have to face. The one thing you need most is support.

Statistics show that the highest percentage of pediatric AIDS cases in the years to come will be from $I V$-drug-user mothers. These children will, in all likelihood, be abandoned in our hospitals. Who will pay for their care? Must these children be abandoned to live in hospitals because there is no residence facility to send them to while a foster home is found? Must the families of children cared for in their homes be forced underground?

Any facility that receives government funding should not be allowed to discriminate against these AIDS victims.

Response on a federal and city level to the magnitude of pediatric AIDS has been extremely slow. Please, let us stop dragging our feet, and let us act responsibly now.

During World War II the federal government with our allies was able to bring together the best scientific minds in the world to develop the atomic bomb. Well, we are at war now and our allies are the world health community. We need to bring together the best scientific minds in the world-not just in our country-to fight this killer. We need the best researchers, clinicians, and scientists under the same roof on a daily basis. We cannot continue to ask these people to spend months filling out grant applications to fund their work.

Three years ago I made a promise to my daughter. She became frightened one evening that she couldn't remember Sam's voice-afraid that she was beginning to forget him. I promised her then that her father and I would not let Sam be forgotten. You see, we hear his voice all the time.

'Presented at the Surgeon General's Workshop on Children with HIV Infection and Their Families, held at the Children's Hospital of Philadelphia, April 6-9, 1987. From the Report of the Surgeon General workshop on children with HIV infection and their families, U.S. Department of Health and Human Services, Public Health Services, Health Resources and Services Administration, Bureau of Health Care Delivery and Assistance, Division of Maternal and Child Health. DHHS Publication No. HRS-D-MC 87-1. 


\section{In every small town, you'll find a church, an American flag, and someone who'll sell you cocaine.}

It's a sad fact, but a fact nonetheless. Substance abuse is so widespread these days that buying cocaine is almost as easy as buying a hot dog or a new pair of shoes.

As a physician, you're in the unique position to detect drug abuse in your patients, using your training, thorough work-ups, and advanced diagnostic techniques.

Through increased detection, you can help curb this growing problem, and help make our towns (both small and large) a home for people, not pushers.

Looking for drug abuse-make it a habit.

Partnership for a Drug-Free America

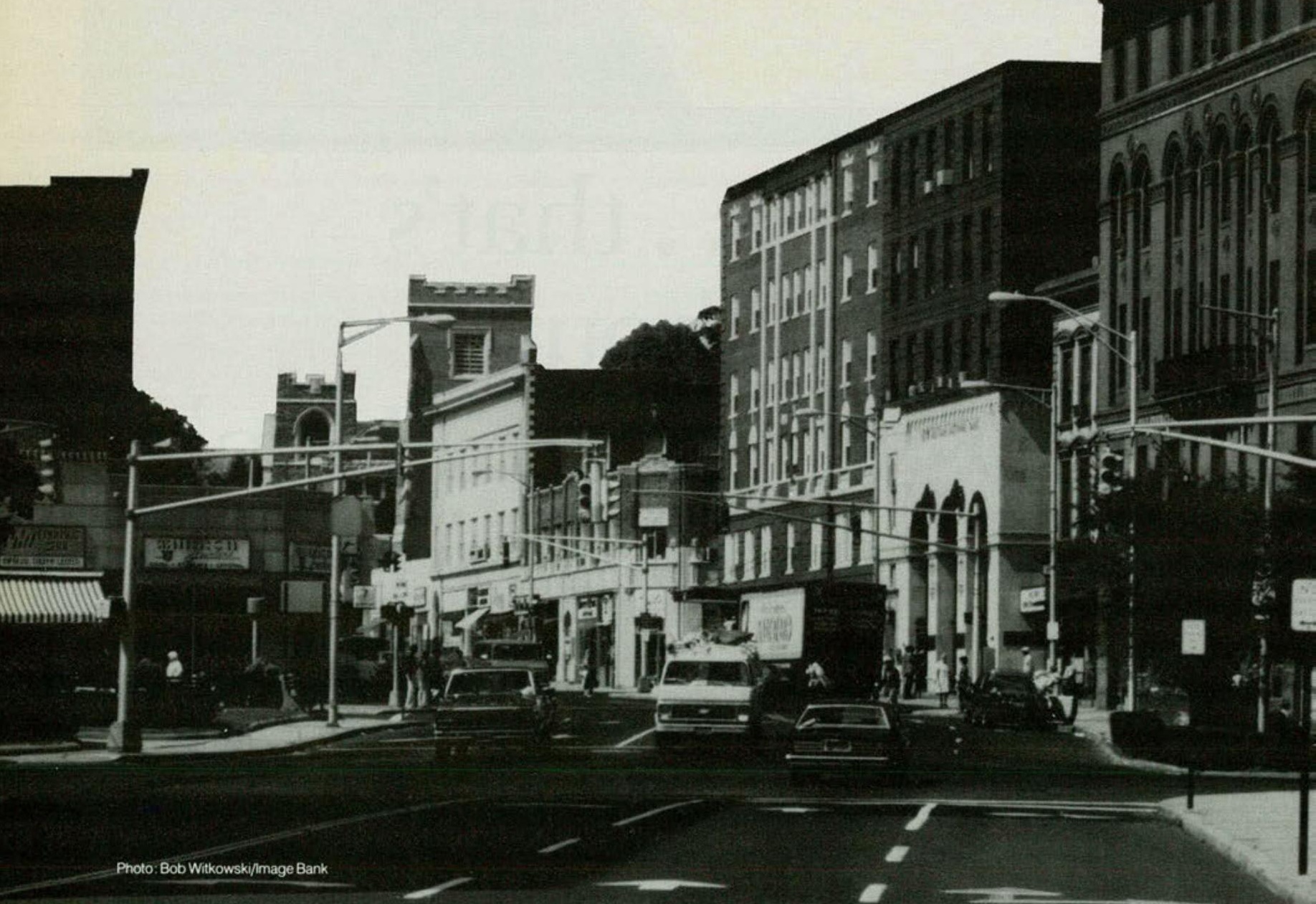

